\title{
TWO-PHASE THREE-WIRE SHUNT ACTIVE POWER FILTER CONTROL BY USING THE SINGLE-PHASE P-Q THEORY
}

\author{
Pablo C. S. Furtado*, Márcio C. B. P. Rodrigues ${ }^{*, \dagger}$, Henrique A. C. Braga*, Pedro G. Barbosa* \\ ${ }^{*}$ Federal University of Juiz de Fora, Power Electronics and Automation Group \\ Juiz de Fora - MG, Brazil \\ ${ }^{\dagger}$ Federal Institute of Education, Science and Technology of Southeast of Minas Gerais \\ Juiz de Fora - MG, Brazil \\ e-mails: pablofurtado@ieee.org, marcio.carmo@ifsudestemg.edu.br, henrique.braga@ufjf.edu.br, pedro.gomes@ufjf.edu.br
}

\begin{abstract}
This paper presents a study of a shunt active power filter (APF) to be applied to two-phase three-wire electric networks. The application of this new APF is presented and possible topologies are discussed. The control algorithm of the APF is based on the single-phase $p-q$ theory, which is briefly reviewed. Then, alternative $-\alpha \beta$ transformations for voltages and currents are proposed to implement the single-phase $p-q$ calculations. These adaptations are followed by the description of the proposed current reference calculation algorithm. Digital simulation and experimental results validate the effectiveness of the proposed shunt APF and control algorithm in compensating current harmonics, reactive power and imbalances of two-phase three-wire loads, even under distorted mains voltage condition.
\end{abstract}

Keywords - Active Power Filters, Electric Vehicles, Power Conditioning, Power Quality, The $p-q$ Theory, Two-Phase Electric Systems.

\section{INTRODUCTION}

In the last decades, the number and variety of appliances electronically controlled have drastically changed home and business environments of modern societies. Power electronics drives for heating, ventilation and air conditioning, washing machines, refrigerators, home running systems, electric stoves and cookers, microwave ovens and, more recently, wide screen LCD TV sets, notebooks, tablets, smart phones, compact fluorescent lamps or led based lighting systems are examples of these devices.

Besides of the increase of electricity consumption, a great number of these new loads are fed by power electronic converters draining non-sinusoidal currents from the electric mains. These distorted currents cause power quality problems such as voltage distortion, electromagnetic interference and malfunction of communication and instrumentation equipment, overload and overheating of electric distribution feeders and transformers, among others [1]-[3].

Passive, active and hybrid power filters are power conditioning devices to be connected in parallel and in series with the electrical network. They are designed to filter harmonics, improving power quality indexes [4]-[6].

The principles of active power filters (APF) were proposed at the ending of 70's and in the beginning of 80's [7], [8]. Different converter topologies and control algorithms have been widely studied and reported in technical literature for shunt and series APF [4], [6], [9].

Manuscript received 24/02/2014; revised 07/04/2014; accepted for publication 19/08/2014, by recommendation of the Special Section Editor Mário L. da S. Martins.
Shunt APF are power electronics converters specially designed and controlled to synthesize harmonic currents on its output terminals to compensate distorted currents drained by nonlinear loads. They can also be controlled to compensate reactive power at the load terminals or demanded by the power system [10].

Despite the number of works about three-phase APF, efforts were also carried on to develop active filters to mitigate power quality problems in single-phase electrical systems [11], [12]. In this specific type of applications, the single-phase APF is installed at low voltages networks to compensate harmonic currents generated by single-phase loads [4], [11]-[14].

However, the application of APF to compensate two-phase three-wire electric networks (2 phases and neutral) has not been enough explored and reported in the literature. These systems represent a significant portion of residential and commercial electrical installations and, probably due to the cost of the active power filter structure, two-phase APF have been employed to solve problems caused by specific loads like welding machines [15] and ac electrified railways [16].

A potential field for the application of two-phase three-wire shunt APF $(2 \phi 3 w-\mathrm{APF})$ in residential and commercial electricity networks could become real by the use of on-board converters of the electric vehicles as recently proposed in [12], [17]. Since vehicle-to-grid connections are usually made to one or two phases of the power distribution system, this extra functionality could provide a cost reduction when it is compared to the separated implementation of the shunt APF. It can also represent an extra income to the vehicle owner since an ancillary service will be provided to the electric utility system. In this future scenario, the massive application of active power filters on residential and commercial installations can be a way to mitigate power quality problems in distribution networks, minimizing reactive and harmonic power flows, reducing losses and enhancing the capability of active power transfer through the electric feeders.

In this context, this paper presents an algorithm to calculate the reference currents used to control a two-phase three-wire shunt APF. The proposed algorithm is based on the $p-q$ theory definitions for single-phase electrical networks. Section II will show and discuss three converter topologies for the $2 \phi 3 w-\mathrm{APF}$. A brief review of the $p-q$ theory and its adaptation to single-phase networks will be presented in Section III. Section IV describes the algorithm of reference current calculation to control the $2 \phi 3 w-\mathrm{APF}$. Simulation and experimental results are presented in Sections V and VI, 
respectively. Finally, Section VII presents the conclusions of this work.

\section{SYSTEM DESCRIPTION}

Figure 1 shows the block diagram of a typical residential consumer fed by two phases and a neutral wire, where $L_{s}$ is the inductance of each supply feeder. This supply system is derived from the conventional three-phase four-wire ac system. Inside the load block there are line-to-neutral and line-to-line loads. The shunt $2 \phi 3 w-\mathrm{APF}$ is connected to the point of common coupling (PCC) through three inductances $L_{f}$ to limit the APF current ripple [18].

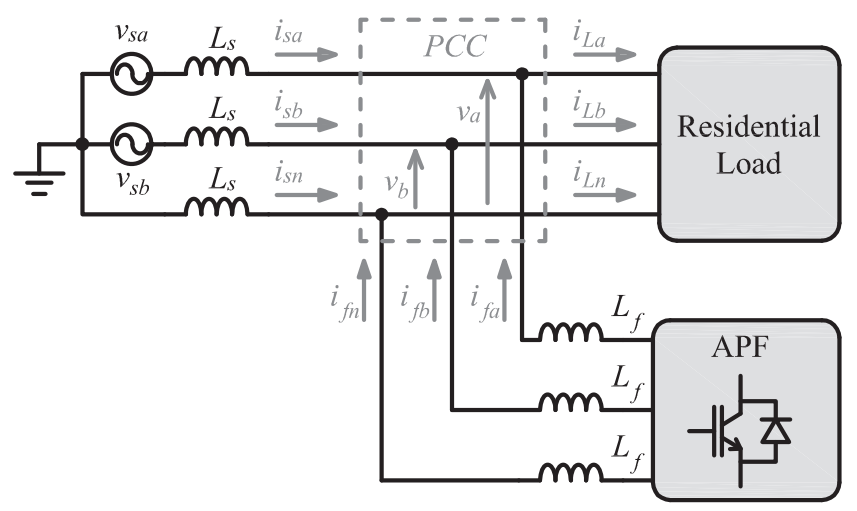

Fig. 1. Two-phase three-wire load and shunt APF connection.

Using the control algorithm that will be shown in this work, based on the sinusoidal compensation strategy, the currents $i_{f a}, i_{f b}$ and $i_{f n}$ synthesized by the $2 \phi 3 w-\mathrm{APF}$ will compensate all the reactive power and the harmonic currents drained by the load. After the compensation, the mains currents become sinusoidal and without any phase delay with respect to each system phase voltage [10].

Figure 2 shows three converter topologies suitable to built the $2 \phi 3 w$-APF [15]. Despite the independent control of the compensating current of each phase, the two single-phase converters of Figure 2.a have the higher number of active switches. They share the same dc capacitor whose average voltage should be at least $3 / 2$ times higher than the ac phase peak voltage [19], [20].

On the other hand, since the two single-phase converters have one of their output terminals connected to the same conductor of the mains, it is possible to share their functionality. This characteristic allows to use the converter shown in the Figure 2.b to synthesize the $2 \phi 3 w-\mathrm{APF}$. This topology has the advantage of using two less active switches. In this case, the dc capacitor voltage should be adjusted to be higher than $3 / 2$ times of the peak value of the ac line voltage [19], [20].

The last option is the converter shown in Figure 2.c. It has the advantage of using the lowest number of semiconductor switches. However the neutral wire should be connected to the midpoint between the two dc capacitors. Thus, each capacitor dc voltage should be setup to be at least equal to $3 / 2$ times of the peak value of the ac line voltage. One disadvantage of this topology is the necessity of equalization of the capacitors de voltages to avoid unsymmetrical output voltages at the ac terminals of the converter [19], [20].

It is also possible to perform an harmonic analysis for the previous converter topologies. The converter of Figure 2.a can be controlled to generate a unipolar output voltage waveform while the only option to modulate the converter of Figure 2.c is by using a bipolar pattern. This characteristic will result in a lower harmonic content for the first topology when it is compared with the last one. For the topology of Figure 2.b, the two phases of the converter can be switched in a synchronous way with the third branch to produce unipolar and bipolar waveforms [21].

Therefore, based on above considerations the topology of Fig. 2.b was chosen to build the $2 \phi 3 w-\mathrm{APF}$ proposed in this work. In the next section it will be presented some concepts about the single-phase $p-q$ theory and its adaptation to calculate reference compensating currents for the shunt $2 \phi 3 w-\mathrm{APF}$.

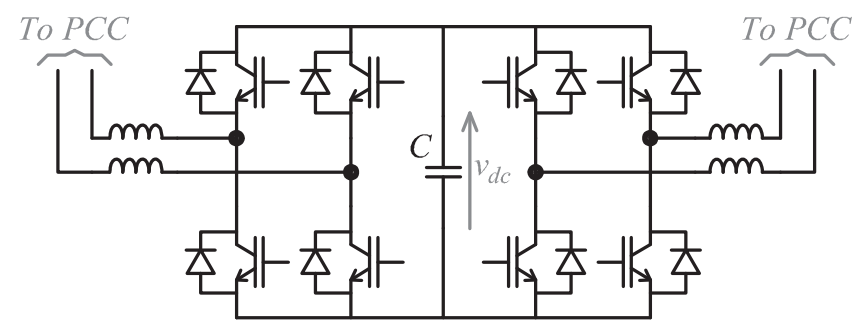

(a)

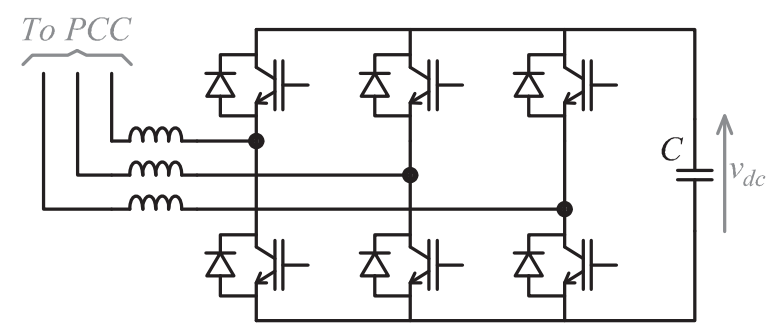

(b)

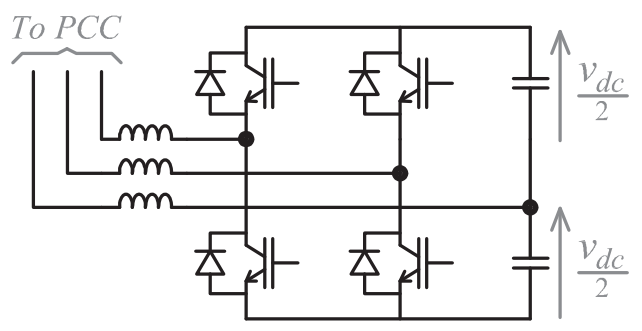

(c)

Fig. 2. VSC topologies: (a) four active branches (2 single-phase VSC); (b) three active branches and (c) two active branches.

\section{BRIEF REVIEW OF THE $P-Q$ THEORY}

The instantaneous power theory, or the $p-q$ theory, has been firstly presented in a japanese conference as a set of power definitions based on instantaneous values of voltages and currents. Since there is no restriction to be imposed 
to the voltages and currents, such definitions are valid for systems containing harmonics or not, and during transients or steady-state conditions. These power definitions are specially useful to calculate reference signals for APFs controllers [10].

Originally developed for three-phase three-wire systems, the $p-q$ theory uses the Clarke Transformation to map instantaneous values of voltages and currents from the natural a-b-c system coordinates into an orthogonal $\alpha-\beta-0$ reference frame coordinate.

According to [10] and considering the system voltages $\left(v_{\alpha}, v_{\beta}, v_{0}\right)$ and currents $\left(i_{\alpha}, i_{\beta}, i_{0}\right)$, in the new reference frame coordinate, it is possible to calculate instantaneous values of real $(p)$, imaginary $(q)$ and zero-sequence $\left(p_{0}\right)$ powers as shown bellow:

$$
\left[\begin{array}{c}
p \\
q \\
p_{0}
\end{array}\right]=\left[\begin{array}{cc:c}
v_{\alpha} & v_{\beta} & 0 \\
v_{\beta} & -v_{\alpha} & 0 \\
\hdashline 0 & 0 & v_{0}
\end{array}\right]\left[\begin{array}{c}
i_{\alpha} \\
i_{\beta} \\
i_{0}
\end{array}\right] .
$$

Each power quantity given by (1) can be separated on their average $\left(\bar{p}, \bar{q}, \overline{p_{0}}\right)$ and oscillating $\left(\tilde{p}, \tilde{q}, \tilde{p_{0}}\right)$ components. They are separated from each other by the use of low-pass filters (LPF). It must be noted that the value of $p_{0}$ will not be null only in three-phase four-wire systems, when the zero-sequence voltage and current have non-zero values [10].

The physical meaning of each power quantity and the complete algorithm to calculate reference compensating currents are thoroughly discussed in [10].

\section{A. Single-Phase $\mathrm{p}-\mathrm{q}$ Theory}

The single-phase $p-q$ theory is an adaptation of the original $p-q$ theory for single-phase systems [22]. It can be also used in three-phase electrical systems. However, in this case, each phase plus the neutral wire should be understood as an independent circuit [22], [23].

The main difference between the original theory and its single-phase $(1 \phi)$ version is the transformation used to get instantaneous values of a single-phase voltage $\left(v_{a}\right)$ and current $\left(i_{a}\right)$ into the $\alpha \beta$ reference frame. In the $1 \phi \mathrm{p}-\mathrm{q}$ theory, variables $v_{\alpha}$ and $i_{\alpha}$ are made equal to the measured phase voltage and current, respectively, while its orthogonal components $v_{\beta}$ and $i_{\beta}$ can be obtained by using a $\pi / 2 \mathrm{rad}$ lead phase shift quadrature filter [14], [24]. The quadrature lead-phase shift filter transfer function is

$$
H(s)=-\left(\frac{1-s T}{1+s T}\right)
$$

where $T=1 / \omega$ and $\omega$ is the system angular fundamental frequency.

Considering the system voltage and current written in the $\alpha \beta$ reference frame, it is possible to use (1) to calculate the instantaneous powers $(p$ and $q$ ) related to the single-phase system. Then, the reference current for the single-phase shunt APF can be calculated by using (1) on its inverse form. The proper selection of power parcels that should be compensated results in

$$
i_{f}^{*}=\left(\frac{v_{\alpha}}{v_{\alpha}^{2}+v_{\beta}^{2}}\right) p_{c}-\left(\frac{v_{\beta}}{v_{\alpha}^{2}+v_{\beta}^{2}}\right) q_{c}
$$

where $i_{f}^{*}$ is the reference current for the shunt $1 \phi$-APF.

As explained before, if the $1 \phi-\mathrm{APF}$ is controlled to compensate all current harmonics and the full reactive power at the load terminals. Then, the compensating powers in (3) should be chosen as $p_{c}=\tilde{p}$ and $q_{c}=q=\bar{q}+\tilde{q}$.

To successfully implement the sinusoidal control strategy, it is necessary to extract the fundamental component of mains voltage in case it is distorted [10], [14]. In this case the reference current for the APF should be calculated by

$$
i_{f}^{*}=\left(\frac{v_{\alpha 1}}{v_{\alpha 1}^{2}+v_{\beta 1}^{2}}\right) \tilde{p}-\left(\frac{v_{\beta 1}}{v_{\alpha 1}^{2}+v_{\beta 1}^{2}}\right) q .
$$

Or, by using the indirect method as follows:

$$
i_{f}^{*}=i_{\alpha}-\left(\frac{v_{\alpha 1}}{v_{\alpha 1}^{2}+v_{\beta 1}^{2}}\right) \bar{p}
$$

where $v_{\alpha 1}$ and $v_{\beta 1}$ are the fundamental frequency components of the single-phase system voltage, already represented in the $\alpha \beta$ reference frame.

\section{CONTROL ALGORITHM OF THE $2 \phi 3 w-\mathrm{APF}$}

The algorithm proposed here treats the $2 \phi 3 w-\mathrm{APF}$ as two independent single-phase APFs with a shared branch which is connected to the mains neutral conductor.

However, before the aforementioned single-phase $p-q$ theory can be applied to calculate the reference signals for the APF some adaptations are proposed. The quadrature filter $H(s)$ is tuned to shift the fundamental frequency component phase by $\pi / 2 \mathrm{rad}$. This expected behaviour will not happen for the harmonics, which will be shifted by different phase angles.

Figure 3 shows an example where a current waveform is transformed into the $\alpha \beta$ coordinates using the filter function given in (2). The usage of the currents waveforms shown in Figure 3 will cause miscalculations of instantaneous powers and then the control algorithm of the APF will generate wrong reference compensating signals.

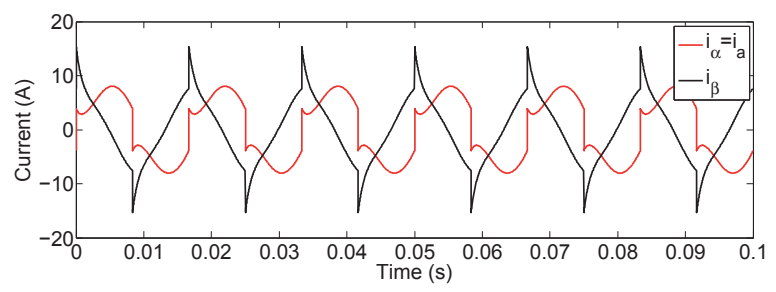

Fig. 3. Current waveforms obtained with $H(s)$.

To overcome the previous problem it will be used an alternative $-\alpha \beta$ transformation. The method consists of defining $i_{\beta}$ equal to the measured phase current. The other current $\left(i_{\alpha}\right)$ is generated by using a buffer that stores a quarter of the cycle of the fundamental frequency of the current $i_{\beta}$. Figure 4 shows the result obtained by using the time delay buffer. The shifted signal is an exact copy of the original waveform. The choice of buffer length, for a given sampling 


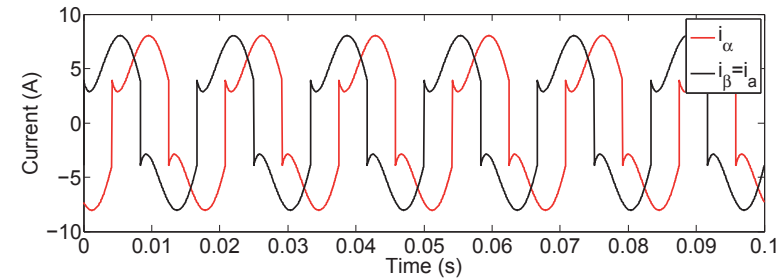

Fig. 4. Current waveforms obtained with the time delay buffer (alternative $-\alpha \beta$ transformation for currents).

frequency, will guarantee the $\pi / 2 \mathrm{rad}$ phase shift for the measured signal.

In the same way as for the current, the voltage $v_{\beta}$ must be defined equal to the measured phase voltage. However, instead of generating a quadrature signal $v_{\alpha}$ by a buffer, this paper proposes the usage of a second-order generalized integrator (SOGI) similiar to that shown in Figure 5 [25].

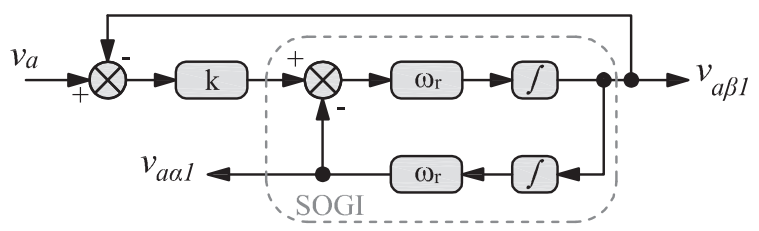

Fig. 5. Second order generalized integrator (SOGI) block diagram.

The use of the SOGI presents some advantages if it is compared with the conventional method (quadrature filter or buffer plus single-phase PLL). Firstly, its design and implementation are quite simple and well described in literature [25]. It does not require buffers to store the measured voltages, diminishing memory usage in the case of digital implementation. It also attenuates the harmonics and generates a quadrature signal simultaneously, improving the performance of the control the algorithm. Thus, SOGI presents the desired capability of filtering and quadrature signal generation in an easily-implementable block structure.

In the $2 \phi 3 w$ system shown in Figure 1, the proposed $\alpha \beta$ transformation must be applied to four quantities: $v_{a}, v_{b}$, $i_{L a}$ and $i_{L b}$ before the single-phase $p-q$ theory can be used. Thus, by applying (1) for each separate phase, four power components are calculated: $p_{a}, p_{b}, q_{a}$ and $q_{b}$, where the subscripts denote each system phase.

The average and oscillatory components of $p_{a}$ and $p_{b}$ have to be separated (using a LPF, for example). The average two-phase active power is then defined by

$$
\bar{p}_{2 \phi}=\bar{p}_{a}+\bar{p}_{b} .
$$

The power components given in (6) will be useful when the $2 \phi 3 w$-APF should compensate load unbalances. According to the proposed adaptations, the currents to be synthesized by each phase of the shunt active filter are given by

$$
\begin{array}{r}
i_{f x}^{*}=\left(\frac{v_{x \beta 1}}{v_{x \alpha 1}^{2}+v_{x \beta 1}^{2}}\right)\left[p_{x}-\left(\frac{p_{d c}+\bar{p}_{2 \phi}}{2}\right)\right]- \\
-\left(\frac{v_{x \alpha 1}}{v_{x \alpha 1}^{2}+v_{x \beta 1}^{2}}\right) q_{x}
\end{array}
$$

where the subscript $x \in\{a, b\}$ and $p_{d c}$ represents an average amount of active power that the $2 \phi 3 w$-APF should drain or inject into the mains to regulate the VSC dc-capacitor voltage [10].

The third reference current, that it is the current that will be synthesized on the neutral conductor, must be calculated by

$$
i_{f n}^{*}=-\left(i_{f a}^{*}+i_{f b}^{*}\right) .
$$

Figure 6 shows the block diagram of the control algorithm of the $2 \phi 3 w-\mathrm{APF}$. Inside each block, it is indicated the number of the equation used as it appears in the text. Two low-pass filters (LPF) with $10 \mathrm{~Hz}$ of cut-off frequency separate the average parts of the instantaneous powers $p_{a}$ and $p_{b}$. An additional loop, with a PI controller, was included in the block diagram to generate the power $p_{d c}$ used to regulate the VSC dc voltage. Three hysteresis current loops guarantee that the compensation currents $\left(i_{f a}, i_{f b}\right.$ and $\left.i_{f n}\right)$ synthesized by the APF track the reference currents $\left(i_{f a}^{*}, i_{f b}^{*}\right.$ and $\left.i_{f n}^{*}\right)$ calculated by (7) and (8), respectively.

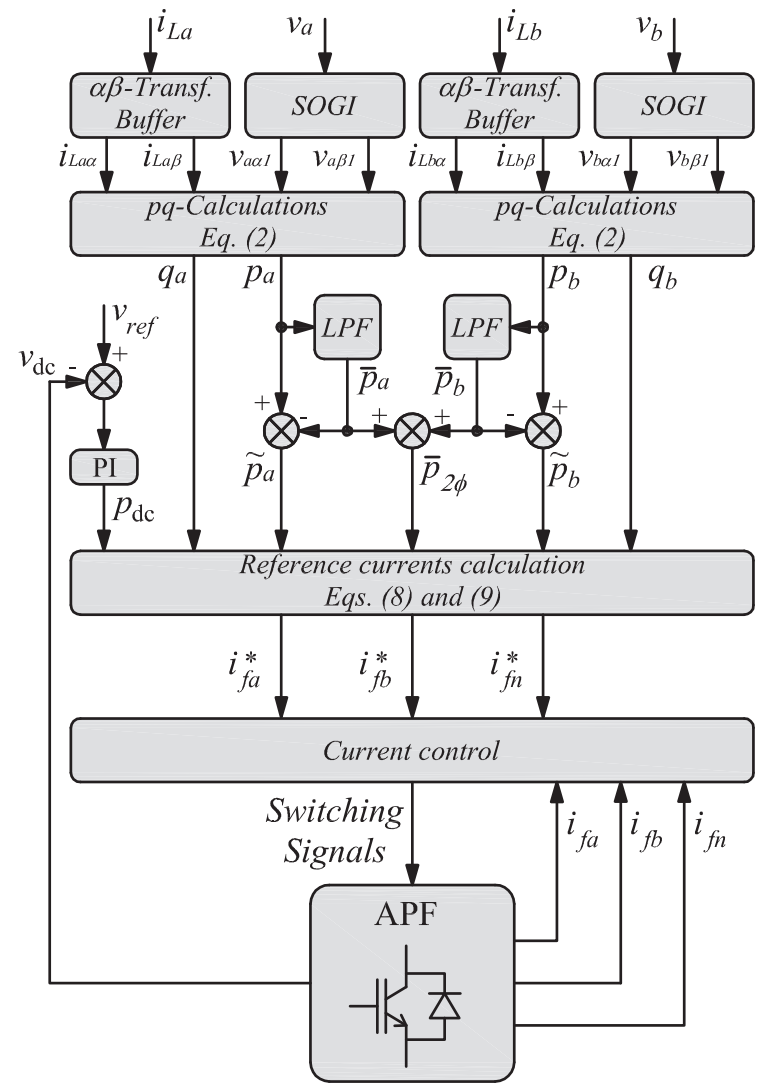

Fig. 6. Block diagram of the control algorithm for the $2 \phi 3 w-\mathrm{APF}$. 


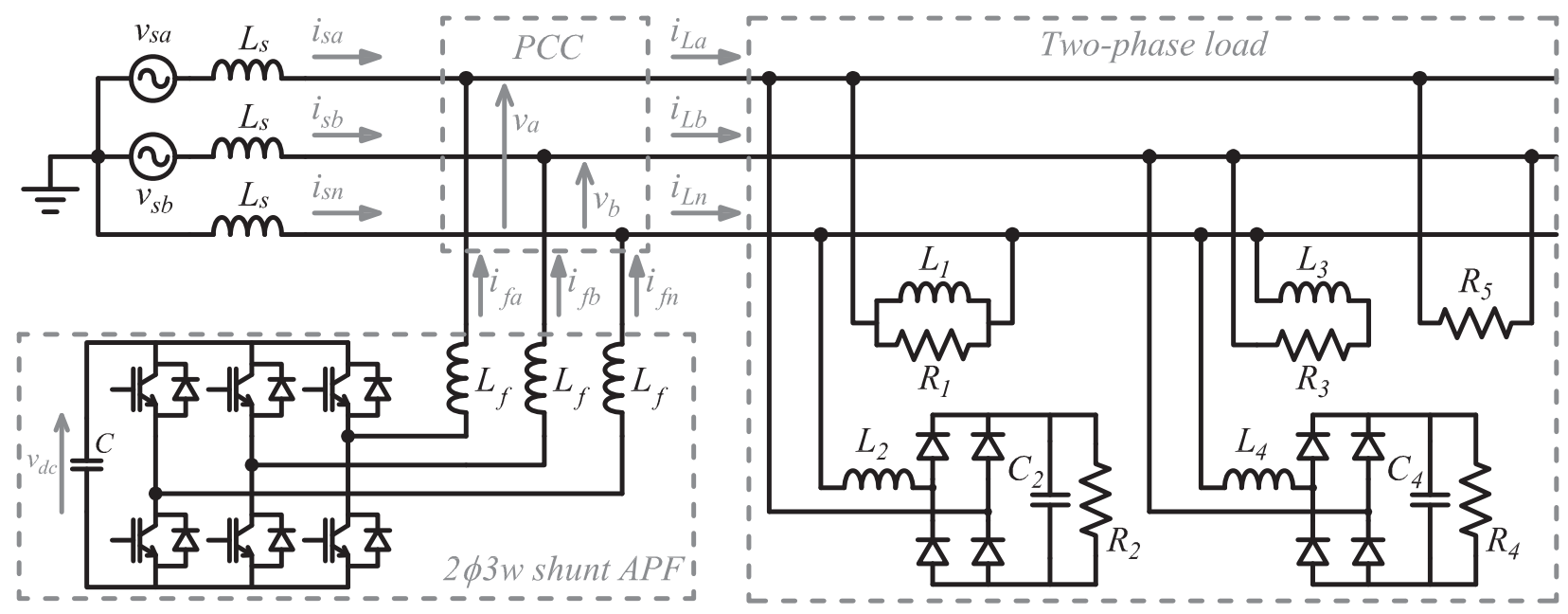

Fig. 7. Setup system for digital simulation studies and experimental validation.

\section{SIMULATION RESULTS}

A digital simulation has been carried out to validate the proposed adaptations and the method to generate reference currents for the $2 \phi 3 w-\mathrm{APF}$. Figure 7 shows the system configuration used to carry out the digital simulation studies. The control algorithm blocks, shown Figure 6, and the current and voltage measuring sensors, as well as their feedback control loops, were not drawn in Figure 7 in order to make it clearer. All the setup system parameters are given in Table I.

At a first glance the reader may question the value of the system voltage shown in Table I. However the electric network shown in Figure 7 was built in the laboratory of the Power Electronics and Automation Group (NAEP) to investigate the impact of the charging and discharging process of the batteries of a small EV (eletric crosskart). So, this choice would allow the comparison of the results obtained with the digital and experimental models of the $2 \phi 3 w-\mathrm{APF}$.

The phase voltages and the load currents at the PCC are measured and sampled with a frequency of $21 \mathrm{kHz}$. The signals of each phase are transformed into their $\alpha \beta$ components before they are used to calculate the instantaneous powers. Then, the instantaneous active powers are separated into their average and oscilating parts and then used to calculate the reference currents for each phase of the $2 \phi 3 w-\mathrm{APF}$

Different types of current controllers can be employed to force the inverter output currents to track their references $\left(i_{f a}^{*}, i_{f b}^{*}\right.$ and $\left.i_{f n}^{*}\right)$ [26]. Since the main goal of this work is the control algorithm of the $2 \phi 3 w-\mathrm{APF}$, an hysteresis controller was used for each phase of the VSC. Despite its variable switching frequency, this controller is easily implemented and it guarantees a very small amplitude error or phase delay for the synthesized current.

The SOGI parameters were designed to be equal to $k=$ 0.35 and $\omega_{r}=377 \mathrm{rad} / \mathrm{s}$. The value of $k$ was chosen to guarantee a good harmonic rejection while the resonance frequency $\omega_{r}$ was made equal to the fundamental angular frequency of the system [25]. Two buffers, with 87 memory
TABLE I

Setup System Parameters

\begin{tabular}{|c|c|c|}
\hline Part of circuit & Configuration & Value \\
\hline Mains & $\begin{array}{l}\text { Two-phase }+ \text { neutral } \\
\text { line voltage }(\mathrm{rms}) \\
\text { phase voltage }(\mathrm{rms}) \\
\text { frequency }\left(f_{1}\right) \\
\text { line resistance }\left(R_{s}\right) \\
\text { line inductance }\left(L_{s}\right)\end{array}$ & $\begin{array}{c}55.0 \mathrm{~V} \\
31.75 \mathrm{~V} \\
60 \mathrm{~Hz} \\
0.01 \Omega \\
50.0 \mu \mathrm{H}\end{array}$ \\
\hline APF & $\begin{array}{l}2 \phi 3 w-\text { VSC } \\
\text { sampling frequency }\left(f_{s}\right) \\
\text { maximum switching freq. }\left(f_{s w}\right) \\
\text { dc voltage }\left(v_{d c}\right) \\
\text { output inductance }\left(L_{f}\right) \\
\text { output resistance }\left(R_{f}\right) \\
\text { hysteresis band }\left(h_{b}\right)\end{array}$ & $\begin{array}{l}21 \mathrm{kHz} \\
21 \mathrm{kHz} \\
100 \mathrm{~V} \\
190 \mu \mathrm{H} \\
20.0 \mathrm{~m} \Omega \\
0.1 \mathrm{~A}\end{array}$ \\
\hline $\begin{array}{l}\text { Load \# } 1 \\
\text { (a-n) }\end{array}$ & $\begin{array}{l}\text { Parallel RL (linear) } \\
\text { Resistance }\left(R_{1}\right) \\
\text { Inductance }\left(L_{1}\right)\end{array}$ & $\begin{array}{l}4.2 \Omega \\
20 \mathrm{mH}\end{array}$ \\
\hline $\begin{array}{l}\text { Load \# } 2 \\
\text { (a-n) }\end{array}$ & $\begin{array}{l}\text { Diode Rectifier (nonlinear) } \\
\text { Input Inductor }\left(L_{2}\right) \\
\text { Output Capacitor }\left(C_{2}\right) \\
\text { Resistive load }\left(R_{2}\right)\end{array}$ & $\begin{array}{c}600 \mu \mathrm{H} \\
1.65 \mathrm{mF} \\
22 \Omega\end{array}$ \\
\hline $\begin{array}{l}\text { Load \# } 3 \\
\text { (b-n) }\end{array}$ & $\begin{array}{l}\frac{\text { Series RL (linear) }}{\text { Resistance }}\left(R_{3}\right) \\
\text { Inductance }\left(L_{3}\right)\end{array}$ & $\begin{array}{l}17 \Omega \\
4 \mathrm{mH}\end{array}$ \\
\hline $\begin{array}{l}\text { Load \# } 4 \\
\text { (b-n) }\end{array}$ & $\begin{array}{l}\text { Diode Rectifier (nonlinear) } \\
\text { Input Inductor }\left(L_{4}\right) \\
\text { Output Capacitor }\left(C_{4}\right) \\
\text { Resistive load }\left(R_{4}\right)\end{array}$ & $\begin{array}{ll}2.9 \mathrm{mH} \\
47 \mu \mathrm{F} \\
33 \Omega\end{array}$ \\
\hline $\begin{array}{l}\text { Load \# } 5 \\
\text { (a-b) }\end{array}$ & $\frac{\text { Series R }}{\text { Resistance }\left(R_{5}\right)}$ & $66 \Omega$ \\
\hline
\end{tabular}

positions each, are used to carry out the $\alpha \beta$ transformations of phase currents as explained in Section IV. They were dimensioned to store $1 / 4$ of the fundamental frequency current waveforms sampled with $21 \mathrm{kHz}$.

The PI controller used to regulate the VSC dc-voltage was designed with a proportional gain and a time constant equal to $20 \mathrm{~W} / \mathrm{V}$ and $2 \mathrm{~W} /(\mathrm{V} . \mathrm{s})$, respectively. These values were chosen to assure a zero steady state error and to block the $120 \mathrm{~Hz}$ ripple common in single-phase applications. The 
presence of this ripple would cause distortion in the reference currents.

Figures 8 and 9 show phase voltages measured at PCC and the SOGI outputs signals for phases $a$ and $b$, respectively. Note that there is a high frequency ripple in the phase voltages due to the switching operation of the VSC. This ripple could be minimized if a LC or LCL filter was connected at the VSC output terminals

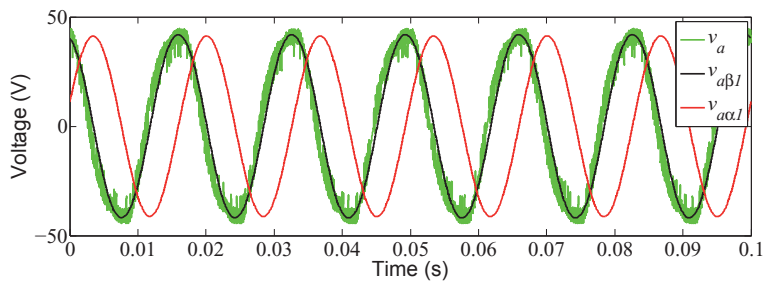

Fig. 8. Phase voltage $v_{a}$ and its $\alpha \beta$ fundamental components.

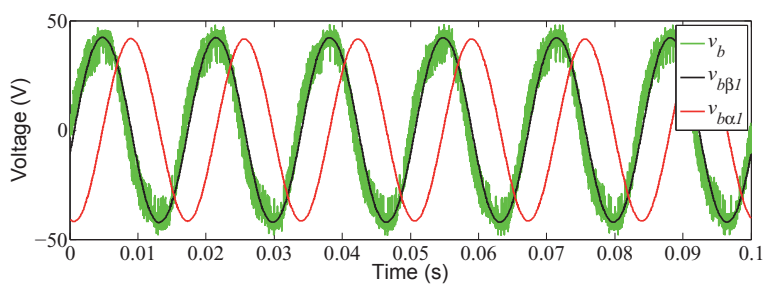

Fig. 9. Phase voltage $v_{b}$ and its $\alpha \beta$ fundamental components.

Figures 10 and 11 show load currents of phases $a$ and $b$, respectively. Each figure shows the measured current and its $\alpha \beta$ components. It can be noted that $\alpha$ components are exact copies of the measured currents, but shifted by $1 / 4$ of period.

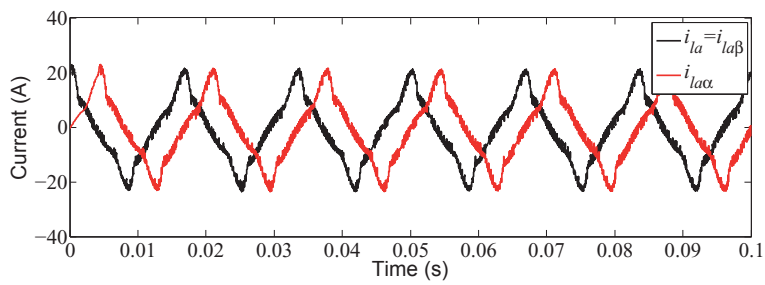

Fig. 10. Phase current $i_{l a}$ waveforms in $\alpha \beta$ frame.

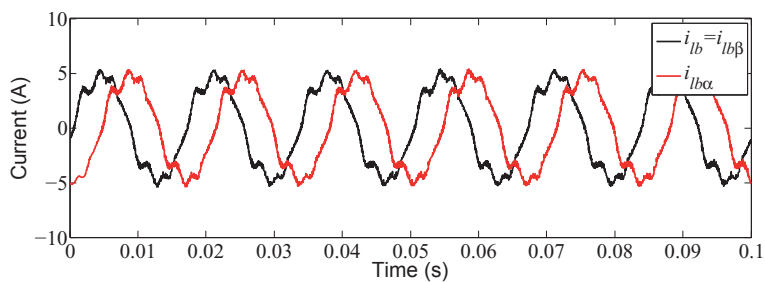

Fig. 11. Phase current $i_{l b}$ waveforms in $\alpha \beta$ frame.

Figure 12 shows the neutral current flowing between the mains and the load in the $2 \phi-$ system. This current is the result of the sum of $i_{l a}$ and $i_{l b}$.

Figures 13,14 and 15 show the phase $a, b$ and the neutral current drained by the compensated load, respectively. After

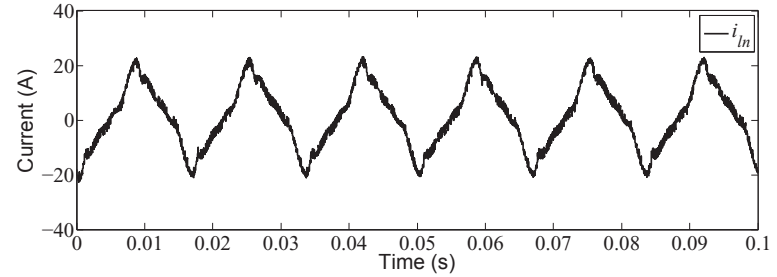

Fig. 12. Neutral current $i_{l n}$ drained by the $2 \phi 3 w$-load.

the $2 \phi 3 w-\mathrm{APF}$ starts its operation the current waveform flowing from each mains phase become sinusoidal and without any phase delay with respect to the phase voltage. The presented waveforms confirm that the proposed method of reference current calculation results in balanced and sinusoidal currents drained from the mains. As for the system voltages, it is possible to observe a high switching ripple in the compensated currents.

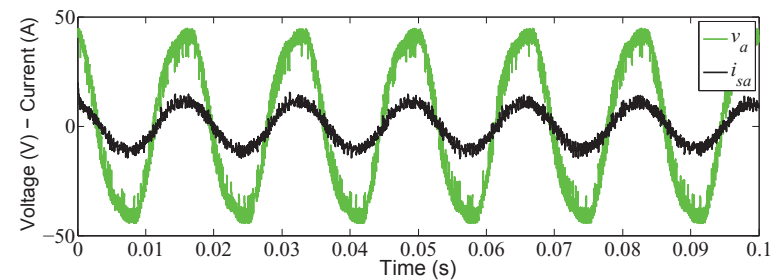

Fig. 13. Phase voltage $v_{a}$ and the compensated source current $i_{s a}$.

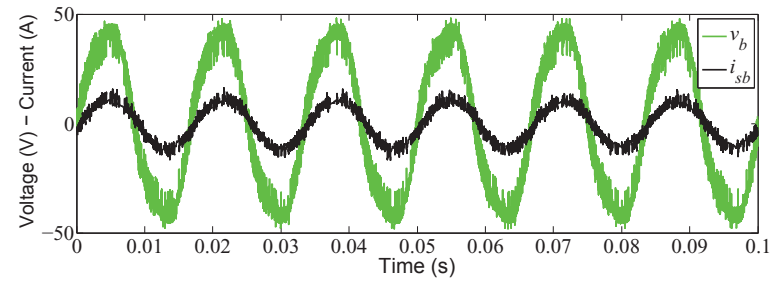

Fig. 14. Phase voltage $v_{b}$ and the compensated source current $i_{s b}$.

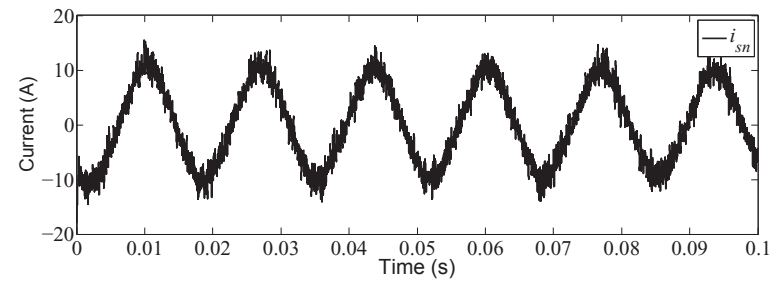

Fig. 15. Compensated neutral current drained from the mains.

The results presented in this section validate the proposed control algorithm. They also confirm that the compensating currents are balanced in a $2 \phi 3 w$-system. In the next section it will be presented the results obtained with the experimental implementation of such system.

\section{EXPERIMENTAL RESULTS}

As explained before, the electric network shown in Figure 7 was built in laboratory to investigate the impact of 
the connection of a small EV. In this scenario, the embedded converter of a small EV (electric kart cross) had its internal controller changed to operate as a $2 \phi 3 w-\mathrm{APF}$. The VSC uses three IGBT modules (SKS200B6CI73V03) manufactured by Semikron. The whole control algorithm for the $2 \phi 3 w-\mathrm{APF}$ was implemented in a floating point digital signal processor (DSP) TMS320F28335 of Texas Instruments.

The system phase voltages and the currents drained by the load in phase $a$, phase $b$ and neutral are shown in Figures 16, 17 and 18, respectively. Note that $i_{l a}$ presents higher amplitude and distortions when it is compared to $i_{l b}$. The neutral current is also highly distorted. The current in phase $a$ is also phase delayed with respect to the phase voltage.

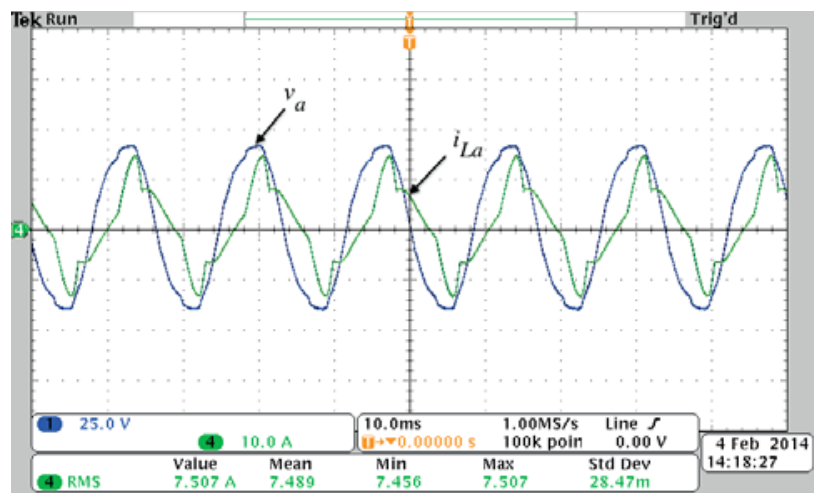

Fig. 16. Experimental mains voltage and load current - phase $a$.

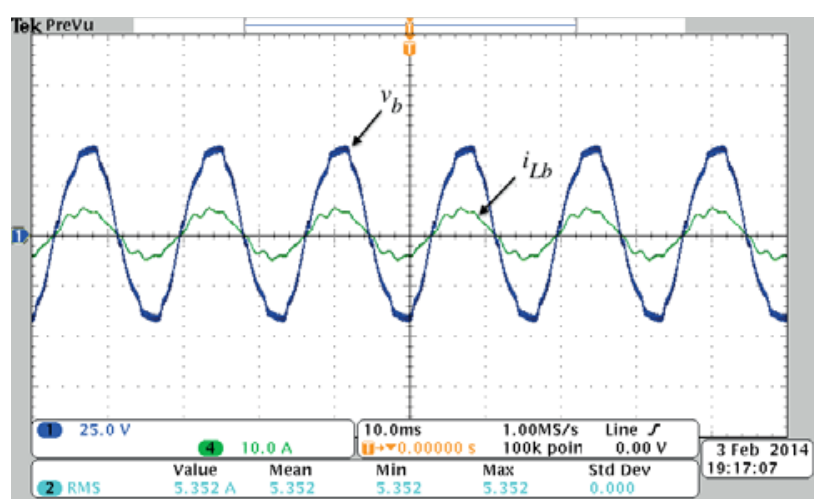

Fig. 17. Experimental mains voltage and load current - phase $b$.

By performing the proposed control strategy, the $2 \phi 3 w$-shunt APF injects the current waveforms shown in Figure 19 into the PCC phases $a, b$ and neutral conductor, respectively. The compensated current waveforms, that is, those drained from the two-phase voltage source phases $a, b$ and neutral are respectively presented in Figures 20, 21 and 22.

Despite the distorted voltage at PCC, the compensated currents are almost sinusoidal. This behavior is explained by the operation of the SOGIs. They extract the fundamental component of each system phase voltage before they are used by the control algorithm. As observed in the digital simulation results there are high order harmonics in system voltages due to the switching operation of the VSC. Also, these currents

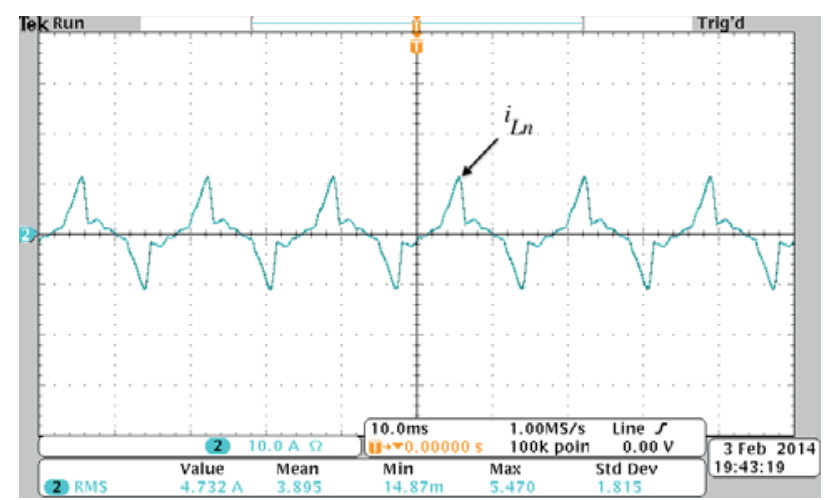

Fig. 18. Experimental load current - neutral.

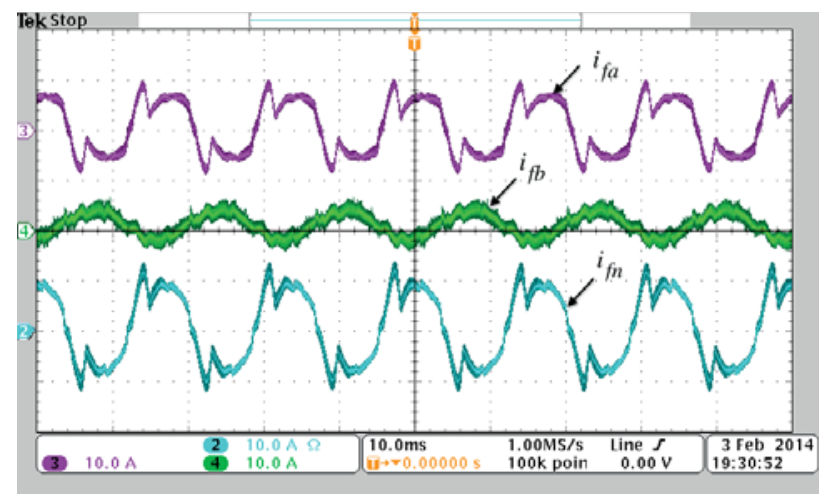

Fig. 19. Experimental $2 \phi 3 w$-shunt APF synthesized currents.

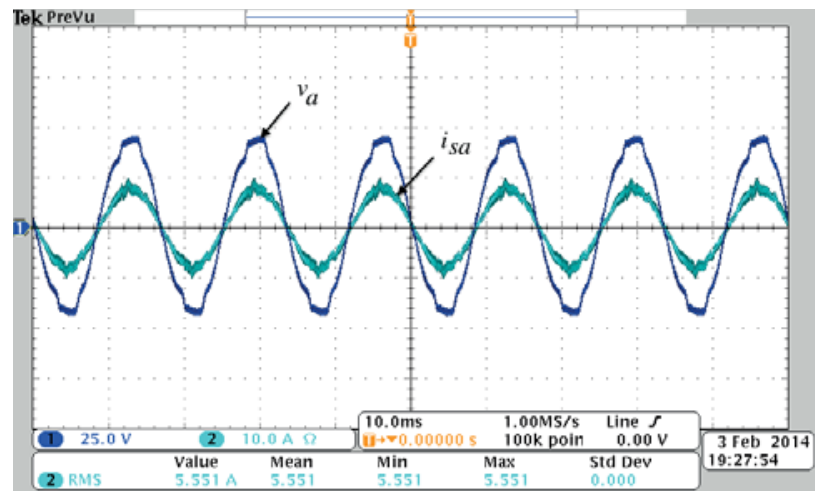

Fig. 20. Experimental voltage and source current - phase $a$.

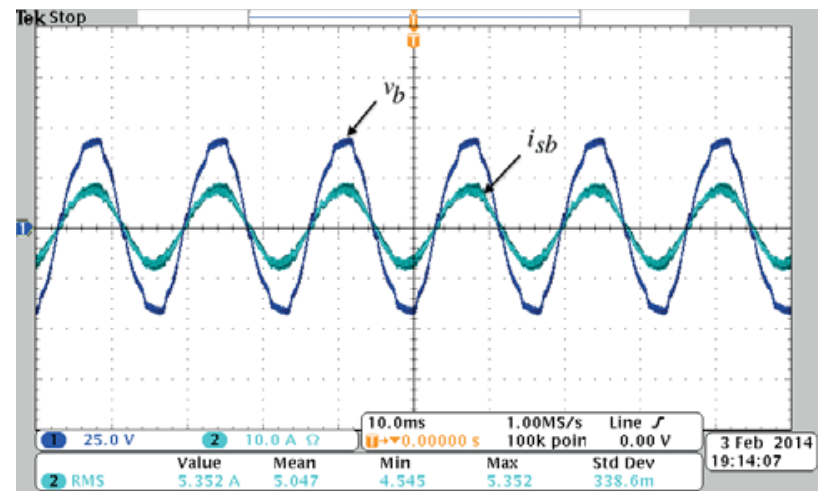

Fig. 21. Experimental voltage and source current - phase $b$. 
are in phase with fundamental phase voltages. That is result of the adopted sinusoidal control strategy and it means the power delivered by the mains is mainly active power in the fundamental frequency. Additionally, these results show the effectiveness of the $2 \phi 3 w-\mathrm{APF}$ in compensating load imbalances, since currents in phases $a$ and $b$ have nearly the same amplitude.

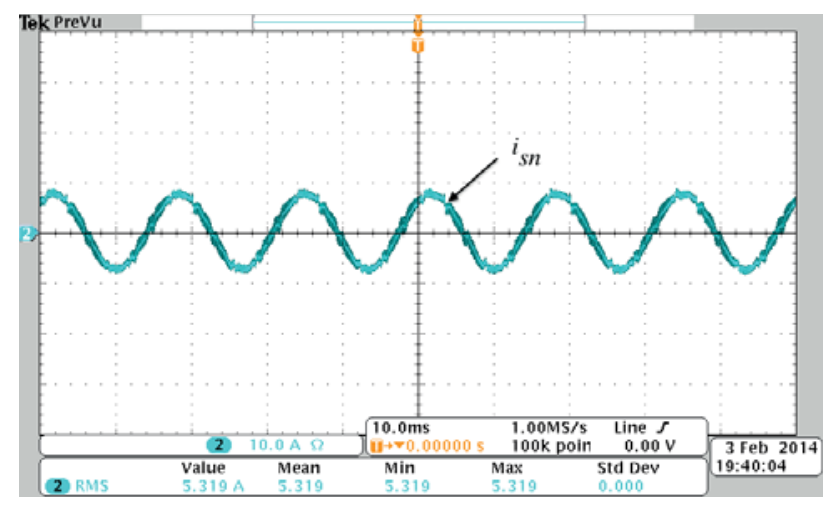

Fig. 22. Experimental source current - neutral.

Quantitative results are presented in Table II, in which the experimentally measured Total Harmonic Distortion (THD) of load and compensated source currents are shown. It can be noted a substantial difference of THD between load and source, specially in phase $a$, which contains more non-linear characteristics, and in the neutral conductor.

TABLE II

Currents Total Harmonic Distortion

\begin{tabular}{ccc}
\hline Phase & Load & Source \\
\hline$a$ & $29.71 \%$ & $5.26 \%$ \\
\hline$b$ & $10.61 \%$ & $4.55 \%$ \\
\hline$n$ & $52.42 \%$ & $5.25 \%$ \\
\hline
\end{tabular}

\section{CONCLUSION}

This paper discussed the concept of two-phase three-wire shunt active power filter. It was discussed that this kind of equipment may find new applicabilities in grid-connected electric vehicles. Also, this paper briefly reviewed the three-phase and single-phase $p-q$ theories used to control active power filters. Adaptations have been proposed to the implementation of single-phase $p-q$ theory, specially alternative single-phase $\alpha \beta$ transformations for currents and voltages. These adaptations improved instantaneous power calculations. Also, the algorithm to calculate reference currents for the $2 \phi 3 w-\mathrm{APF}$ has been described. The proposed algorithm aims to control this APF in order to fully compensate current harmonics, reactive power and imbalances of a $2 \phi 3 w$-load, even under distorted mains voltages.

Computational simulation results have confirmed the effectiveness of the proposed algorithm for reference signals calculations. Moreover, a reduced-scale prototype has been developed in laboratory in order to verify the discussed concepts experimentally. The obtained results confirmed the simulation results, allowing a two-phase mains to feed a non-linear, reactive and imbalanced load with sinusoidal currents with the same amplitude. The comparison of currents THD between load and source showed quantitatively the effectiveness of the two-phase shunt APF.

Future works shall investigate the performance of the proposed algorithm under system frequency variation conditions. Different compensations strategies, such as constant power strategy, may be also studied and useful depending on the application desired to the proposed shunt APF.

\section{ACKNOWLEDGEMENT}

The authors would like to express their gratitude to CAPES, CNPq and FAPEMIG by the partial financial support to realize this work. They would also like to thanks Trancil for the donated equipment and the undergraduated students Thais Peres and Igor Souza for their contributions.

\section{REFERENCES}

[1] D. D. Sabin, A. Sundaram, "Quality enhances reliability [power supplies]," IEEE Spectrum Magazine, vol. 33, no. 2, pp. 34-41, Feb. 1996.

[2] R. Redl, P. Tenti, J. D. van Wyk, "Power electronics' polluting effects," IEEE Spectrum Magazine, vol. 34, no. 5, pp. 32-39, May. 1997.

[3] I. A. Pires, "Caracterização de harmônicos causados por equipamentos eletro-eletrônicos residenciais $e$ comerciais no sistema de distribuição de energia elétrica," Master's thesis, Universidade Federal de Minas Gerais, Belo Horizonte, Brazil, 2006, (in Portuguese)

[4] B. Singh, K. Al-Haddad, A. Chandra, "A review of active filters for power quality improvement," IEEE Transactions on Industrial Electronics, vol. 46, no. 5, pp. 960-971, Oct. 1999.

[5] F. Z. Peng, P. Zhiguo, W. Suilin, A. Hiruma, "Power factor correction using a series active filter," in Proc. of 34th Annual IEEE Power Electronics Specialist Conference (PESC'2003), pp. 1500-1504, 2003.

[6] E. C. dos Santos, C. B. Jacobina, J. A. A. Dias, N. Rocha, "Single-phase to three-phase universal active power filter," IEEE Transactions on Power Delivery, vol. 26, no. 3, pp. 1361-1371, July 2011.

[7] L. Gyugyi, E. C. Strycula, "Active ac power filters," in Proc. of IEEE/IAS Annual Meeting, pp. 529-535, 1976.

[8] H. Akagi, Yoshihira Kanazawa, A. Nabae, "Instantaneous reactive power compensators comprising switching devices without energy storage components," IEEE Transactions on Industry Applications, vol. IA-20, no. 3, pp. 625-630, May. 1984.

[9] A. Bhattacharya, C. Chakraborty, S. Bhattacharya, "Shunt compensation: reviewing traditional methods of reference current generation," IEEE Industrial Electronics Magazine, vol. 3, no. 3, pp. 38-49, Sep. 2009. 
[10] H. Akagi, E. H. Watanabe, M. Aredes, Instantaneous Power Theory and Applications to Power Conditioning, John Wiley \& Sons, Inc., 1st Edition, New Jersey, 2007.

[11] W. R. N. Santos, E. R. C. da Silva, C. B. Jacobina, E. de M. Fernandes, A. C. Oliveira, R. R. Matias, D. F. G. Filho, O. M. Almeida and P. M. Santos, "Single-phase active power filters with reduced number of power switches and optimum voltage control angle," Revista Eletrônica de Potência (SOBRAEP), vol. 18, no. 4, pp. 1215-1223, Nov. 2013.

[12] M. C. B. P. Rodrigues, H. J. Schettino, A. A. Ferreira, P. G. Barbosa, H. A. C. Braga, "Active power filter operation of an electric vehicle applied to single-phase networks," pp. 1-8, Nov. 2012.

[13] M. El-Habrouk, M. K. Darwish, P. Mehta, "Active power filters: a review," IEE Proc. of Electric Power Applications, vol. 147, no. 5, pp. 403-413, Sep. 2000.

[14] V. Khadkikar, A. Chandra, B. N. Singh, "Generalised single-phase $p-q$ theory for active power filtering: simulation and dsp-based experimental investigation," IET Power Electronics, vol. 2, no. 1, pp. 67-78, Jan. 2009.

[15] H. Hojabri, H. Mokhtari, "A new power quality enhancement method for two-phase loads," in Proc. of International Conference on Power Electronics Drives and Energy Systems (PEDES'06), pp. 1-5, 2006.

[16] T. Tanaka, M. Okamoto, E. Hiraki, "Control strategies of active power line conditioners in single-phase circuits," in Proc. of IEEE 8th International Conference on Power Electronics and ECCE Asia (ICPE ECCE 2011), pp. 1813-1820, 2011.

[17] M. C. B. P. Rodrigues, A. A. Ferreira, P. G. Barbosa, H. A. C. Braga, "Electric vehicles as power quality improvement resources in residential electricity networks," in Proc. of 1st Power Electronics South America Conference, pp. 1-8, 2012.

[18] T. Thomas, K. Haddad, G. Joos, A. Jaafari, "Design and performance of active power filters," IEEE Industry Applications Magazine, vol. 4, no. 5, pp. 38-46, Sep. 1998.

[19] A. Nasiri, S. B. Bekiarov, A. Emadi, "Reduced parts single-phase series-parallel ups systems with active filter capabilities," in Proc. of The 25th International Telecommunications Energy Conference (INTELEC'2003), pp. 366-372, Oct. 2003.

[20] A. Nasiri, A. Emadi, "Different topologies for single-phase unified power quality conditioners," in Proc. of 38th IEEE IAS Industry Applications Conference, pp. 976-981, Oct. 2003.

[21] N. Mohan, T. Undeland, W. P. Robbins, Power Electronics: Converters, Applications and Design, John Wiley \& Sons, Inc., 2nd Edition, New York, 1995.

[22] M. T. Haque, "Single-phase pq theory," in Proc. of IEEE Power Electronics Specialists Conference (PESC'2002), pp. 1815-1820, 2002.

[23] M. T. Haque, "Single-phase pq theory for active filters," in Proc. of IEEE Region 10 Conference on Computers, Communications, Control and Power Engineering, pp. 1941-1944, 2002.
[24] M. T. Haque, T. Ise, "Implementation of single-phase pq theory," in Proc. of the Power Conversion Conference (PCC-Osaka), pp. 761-765 vol.2, 2002.

[25] P. Rodriguez, R. Teodorescu, I. Candela, A.V. Timbus, M. Liserre, F. Blaabjerg, "New positive-sequence voltage detector for grid synchronization of power converters under faulty grid conditions," in Proc. of 37th IEEE Power Electronics Specialists Conference(PESC'2006), pp. 1-7, June 2006.

[26] F. T. Ghetti, P. G. Barbosa, A. A. Ferreira, H. A. C. Braga, "Estudo comparativo de técnicas de controle de corrente aplicadas a filtros ativos shunt," in Congresso Brasileiro de Automática (CBA’2010), vol. 1, pp. 3701-3708 (In Portuguese), 2010.

\section{BIOGRAPHIES}

Pablo Carlos de Siqueira Furtado graduated in electrical engineerging at the Catholic University of Petrópolis, Petrópolis, Brazil, in 2012. Currently, he is a graduate student of the Federal University of Juiz de Fora Electrical Engineering Program, Juiz de Fora, Brazil. His interests are related to active power filters, static power compensators, electric vehicles and power quality.

Márcio do Carmo Barbosa Poncílio Rodrigues was born in Cataguases, Brazil, in 1978. He received the B.S. and M.S. degrees in electrical engineering from the Federal University of Juiz de Fora (UFJF), Brazil, in 2002 and 2004, respectively. He is now a professor at the Federal Institute of Education, Science and Technology of Southeast of Minas Gerais, Brazil. Also, he is currently working towards his $\mathrm{PhD}$ degree at Power Electronics and Automation Group of UFJF. His main research interests include electric vehicles, active power filters and renewable energy systems.

Henrique Antônio Carvalho Braga received the B.S. degree in electrical engineering from the Universidade Federal de Juiz de Fora (UFJF), Brazil, in 1982; the Master Degree from COPPE-UFRJ, in 1988 and the Dr. Eng. degree from UFSC, in 1996. From 2005 to 2006 he was enrolled in a post-doctoral cooperation at Universidad de Oviedo, Gijon, Asturias, Spain. Since 1985, he has been teaching Basic Electronics and Power Electronics at UFJF, in undergraduate and graduate levels. Prof. Braga's research interests are mainly related to the Power Electronics field, mainly concerning high power factor converters, LED drivers and renewable energy systems. Prof. Braga is a member of SBA, Sobraep and IEEE.

Pedro Gomes Barbosa received the B.S. degree in electrical engineering from the Federal University of Juiz de Fora, Juiz de Fora, Brazil, in 1986, and the M.Sc. and the D.Sc. degrees in electrical engineering from the Federal University of Rio de Janeiro, Rio de Janeiro, Brazil, in 1994 and 2000, respectively. Currently, he is Associate Professor of the Federal University of Juiz de Fora, Juiz de Fora, Brazil. His main research interests are modeling and control of power electronics converters, integration of renewable energy sources, electric vehicles applications, active power filters and static power compensators. 